\title{
Transición o Simulación: los partidos políticos en México
}

\author{
Guadalupe Lizárraga \\ Unidad Académica Profesional de Zumpango, UAEM
}

Después de la Segunda Guerra mundial, la transformación de los sistemas políticos autoritarios a democráticos se ha vuelto un imperativo para la mayoría de los estados nacionales de nuestro tiempo. La democracia liberal como forma de organización estatal cobró mayor legitimidad después de la desaparición de la URSS. Las dictaduras militares se han extinguido gracias al proceso de aislamiento - en el mejor de los casos - al que han sido sometidas, como Haití, el caso más reciente, sin que se llegase a la intervención militar por parte de la ONU. Otro proceso de transición dramático ha sido el de Sudáfrica, pero bastante confortador por su desenlace pacífico, después de décadas de cruentas luchas. ${ }^{1}$ Así también, nos recuerda la historia latinoamericana de casos como El Salvador, donde el costo de la democracia fue de diez años de guerra. Memoria dolorosa e imborrable, que ha dotado de prudencia y tolerancia a las diversas fuerzas políticas para acelerar su proceso de transición a una configuración democrática estable y sólida.

Si pensamos a grandes rasgos en configuraciones estatales democráticas en vías de consolidación, es decir, en democracias en el sentido occidental y no en gobiernos emanados de elecciones y aperturas acotadas de regímenes, podemos señalar que la mayoría de los países latinoamericanos son semidictaduras, autocracias disimuladas o democracias aparentes, y en casos contados, donde los gobiernos son emanados de elecciones auténticas, podemos apenas ubicarlos como democracias en transición, porque, aun cuando se requiera de reformas políticas más completas para denominarlas como tales, el paso fundamental lo han dado: la universalización del sufragio y su respeto efectivo, a diferencia de las democracias aparentes donde se recurre invariablemente a usos fraudulentos para alterar las preferencias electorales de los individuos.

México no ha estado pasivo ante esta «tercera ola democratizadora». (Huntington, 1993) El juego de los actores políticos mexicanos se ha conformado dentro de un ámbito discursivo en el que el «democratismo» y el

1 Este punto parecería una contradicción, pues hablamos de desenlace pacífico después de las innumerables ejecuciones, torturas, secuestros y mutilaciones. Pero estamos frente a una diferencia conceptual entre revolución, transición y reforma que abordaré más adelante. 
«reformismo» han penetrado en todas las capas de las diversas estructuras del sistema político, de manera tal que parecería que nuestro país vive -como si estuviera en su mejor momento- un proceso efectivo de transición política. Sin embargo, hay suficientes razones para sostener, en este caso, que nos encontramos ante la sola apariencia de un proceso democratizador; en contraste, apenas es posible hablar en México de un proceso de liberalización (Dahl, 1989) en el que se ha ampliado el debate público y se ha ampliado la libertad de las actividades políticas, especialmente para la oposición.

En este contexto, sin embargo, la lógica que guía el desempeño de los partidos, en el marco del debate sobre la transición política, tiende poderosamente a convertirlos en agencias profesionalizadas de manipulación, más que, como se esperaría, agencias de expresión (Sartori, 1980) y comunicación de los problemas sociales. Con esta lógica, los impactos futuros en el proceso de transición política y reforma del estado son escasamente optimistas. Esta es la tesis que argumentaré en el presente texto.

\section{Los partidos y la expresión política}

Considero pertinente para los objetivos del texto hacer una breve síntesis de lo ampliamente estudiado por la politología contemporánea, sobre los partidos políticos, para no descuidar la consistencia conceptual en la aplicación del caso que me ocupa, el mexicano.

Panebianco (1990) realiza una crítica a la mayoría de las definiciones de partido que son elaboradas sobre la base de los fines; según este autor, tales definiciones se basan en dos premisas que resultan evidentes por sí mismas para aquellos que las adoptan:

1. Los partidos son grupos que persiguen la obtención de ciertos fines. (Se da por descontado algo que hay que probar).

2. La ideología de cada partido es el mejor indicador de sus fines. (Se da por sentado que -las metas ideológicas- corresponden con los fines reales).

Los fines de los partidos no son evidentes. Además, con respecto a ellos los análisis parten de los prejuicios indicados antes. Como lo ha establecido el propio Panebianco:

"Los partidos -al igual que cualquiera otra organización- se distinguen por el específico ambiente en el que desarrollan una específica actividad. Sean cuales fueran los demás posibles escenarios que comparten con otras organizaciones, sólo los partidos operan en la escena electoral y compiten por los votos. Esto permite distinguir a los partidos por una cierta actividad (ligada a un ambiente determinado) que no tienen en común con ningún otro tipo de 
organización; no prejuzgando el problema de los eventuales fines (dado que una misma actividad pueda servir a fines distintos)." ${ }^{2}$

A partir de aquí podemos sostener que las élites partidistas no siempre maximizan votos aun cuando su ámbito de acción sea el electoral. De hecho, éstas pueden maximizar tantas cosas como intereses aniden en los individuos que las conforman. Quizá sea preciso abundar más en esto. Formal- mente, los partidos presumen querer «acceder al poder», querer gobernar. No obstante, la responsabilidad que en ello está implícita no significa otra cosa más que responder, ya no como partido sino como gobierno, a toda una ciudadanía y no sólo a sus electores, porque, de no hacerlo, existe potencialmente un costo por parte de los ciudadanos: no volverlo a elegir como gobierno en las siguientes elecciones, esto es, un costo electoral. De esta manera, un partido de oposición puede obtener mayores logros legitimadores y ventajas materiales preservándose como oposición y, desde esta postura, desaprobar, criticar, negociar y -en el mejor de los casos- evaluar e incidir en la agenda gubernamental. Lo que se pone en juego son intercambios y favores políticos, que van desde el prebendas dinerarias hasta los votos en iniciativas de ley y puestos en ciertas instancias administrativas de gestión de políticas. Por supuesto que ello no sólo es aplicable a los partidos de oposición, también estos recursos son completamente válidos y útiles para los miembros, con cierta influencia política, del mismo partido que gobierna.

Pero, vayamos a la cuestión planteada como subtítulo de este apartado: ¿Para qué son los partidos políticos? Y Sartori (1980) nos da una aproximación a uno de los papeles que teóricamente juegan dichas organizaciones. Los partidos expresan a la autoridad política una selección del caótico conjunto de problemas sociales. Esto es, los partidos identifican o detectan el conjunto de problemas percibidos por los individuos, miembros de una sociedad, y «abanderan» o hacen suyos una selección de dichos problemas, mediante la construcción discursiva de propuestas de políticas o problemas públicos. A este proceso, el propio Sartori, le ha llamado función expresiva de los partidos.

En ese momento, el de la función expresiva, los partidos políticos apuestan su existencia. Es decir, buscan legitimarse. Es el momento de la persuasión, y por ende, el de la captación de potenciales electores. Mientras más individuos de una determinada población perciban como suyo un problema, más representativo será el partido que lo abandere y, por tanto, crecerá en

2 La actividad específica de una determinada organización no define su objetivo sino de modo circular y reiterativo. Panebianco 1990. 
legitimidad ex ante, ${ }^{3}$ por el sólo hecho de expresar con mayor amplitud los conflictos de los diversos grupos de la sociedad y, así también, habrá mayores posibilidades de captación de votos de dicha población. Sin embargo, ni todos los problemas sociales redundan en una elección, que permita al partido elegido solucionarlos como autoridad política, ni todos los problemas son abanderados, para su solución como respuesta a los demandantes. Los resultados de la función expresiva, es decir, lo que queda colocado como compromisos gubernamentales, no siempre son los esperados por sus demandantes, ni coinciden con lo que prometen los candidatos y las élites partidistas que los abanderan, que los pub licitan o difunden en los medios de comunicación.

Hay un segundo momento que ha solido llamársele «expresión política», que es el momento específico en el que las élites partidistas negocian e inciden en la formación de la agenda gubernamental. En el proceso político, los partidos cuentan con un recurso decisivo que les da poder: el manejo sobre flujos específicos de información. Los partidos son los legítimos canales de expresión de las preferencias ciudadanas y de los problemas sociales; los partidos son manejadores de información públicamente pertinente. El peso en la opinión pública de los partidos debido a ello es considerable. De tal suerte que la persuasión y los intercambios dependen en una importante medida del grado del manejo comunicacional. Esto es, a mayor manejo comunicacional, mayor será la capacidad de persuasión y mayor será la posibilidad de ser sujeto de intercambios políticos. Lo cual se traduce en influencia y poder.

Lo anterior, pues, nos resulta pertinente para en lender el proceso en el que están inmersos los partidos políticos al momento de expresar frente a la autoridad política los problemas sociales. Los dirigentes de las organizaciones partidistas canalizan a los medios de comunicación la selección hecha del conjunto de cuestiones o problemas. Si los dirigentes tienen un manejo comunicacional eficaz, lograrán que sus demandas formen parte de la opinión pública. Desde el momento que logran introducir sus temas o prioridades en la opinión pública empiezan a crecer en credibilidad, que posteriormente se traduce en legitimidad ante sus adeptos, además, de la alineación de otros grupos sociales al identificarse con determinadas demandas, necesidades o problemas e incluso con las «mentalidades» (en el sentido ideológico) de los dirigentes. Sus temas, al tener tal resonancia, pueden utilizarlos como recursos de presión a la autoridad gubernamental. Ello les da a los partidos un

3 Todo sujeto político tiene una pretensión de legitimidad, Weber 1964. Sin embargo, hablo de legitimidad ex ante por la capacidad del liderazgo del partido para expresar los suficientes estímulos a determinados grupos sociales, de manera tal, que éstos reconozcan incuestionablemente en dicho liderazgo la posibilidad veraz de cumplir, independientemente de los atributos carismáticos o de otro tipo que éste posea. 
cierto componente de superioridad, al lograr que el gobierno se convierta en interlocutor obligatorio. Es decir, los partidos, en este momento específico, empujan a la autoridad a negociar o realizar transacciones respecto de las demandas expresadas públicamente.

Es entonces, cuando se da un verdadero «juego del poder ${ }^{4}$ entre partidos, grupos de interés y gobierno. La negociación, o si se quiere, la búsqueda del consenso para definir las prioridades, presuntamente de mayor interés público, no siempre se realiza a la luz de los ciudadanos. Pues tal negociación puede darse de manera oculta, privada, y no en público. Las élites de los partidos pueden imponerse como los Únicos interlocutores legítimos (8) frente a la autoridad. Empero, las probabilidades de intercambios políticos entre aquéllas y el gobierno, a fin de desviar, manipular, retrasar o suprimir las cuestiones o problemas a resolver, son extraordinariamente altas.

Por un lado, los dirigentes partidistas tienen el recurso del manejo comunicacional y, por otro, pueden tener acceso a negociar en secreto con la autoridad formal los asuntos públicos. Ciertamente, estoy planteando una reducción burda del verdadero entramado que urden los actores políticos para extender los límites de sus acciones. Pero, la interferencia de ambos componentes, entre otros, nos arroja una idea aproximada del tipo de respuesta y regateo que pueden dichos actores dar a sus públicos, originalmente, los demandantes.

Sobre la base de lo anteriormente expuesto, deducimos que de los planteamientos «abanderados» en el momento de la función expresiva, para usar los términos de Sartori (1980), al momento de la expresión política -la incidencia de ciertos temas en la agenda gubernamental-, no hay garantía de que exista una correspondencia fiel. Sin embargo, la pretensión de legitimidad de las élites partidistas, por una parte, y los ulteriores costos electorales, por otra, con- vierten a los partidos en efectivos canales de expresión de los problemas sociales, aun cuando su capacidad de gestión y respuesta se vea interferida por la compleja red de relaciones de poder e intercambios.

\section{Los Partidos en el Marco de la Transición Política en México}

Transición es un concepto amplio y complejo que no profundizaré en este texto, por ser el papel de los partidos políticos el tema que me ocupa. El término «transición» ha sido usado, en la politología contemporánea, para designar el proceso en el que interactúan los diversos actores políticos como 4 Denominación que ha usado Lindblom (1991) para referirse a las Interacciones políticas por medio de las cuales se controlan unos a otros. 
protagonistas de la transformación de determinada configuración estatal. Este término está estrechamente liga- do al concepto de reforma, pues se trata de un proceso que se caracteriza por su carácter pacífico, en el sentido de que no es producto de un desenlace violento, sin que con ello quiera implicar que en otro momento no se hayan dado sucesos violentos.

Lo relevante, en todo caso, es que los procesos de transición política en la «tercera ola» de la que habla Huntington (1994), se encuentran articulados con transformaciones de fondo de la configuración estatal, pues se hallan implicados los retos de la globalización de los mercados, contexto que empuja a las élites estatales a reducir significativamente sus déficit tradicionales en materia de racionalidad gubernamental. Especialmente, ése es el caso de las sociedades periféricas -el submundo del atraso- y de las sociedades emergidas del derrumbe del llamado «bloque socialista». No es que haya transición porque haya globalización, sino que las democratizaciones se vuelven imperativas en el nuevo contexto económico mundial.

Esto es, el proceso de transición tiende a adoptar una acción definida como proyecto estatal, es decir, las transiciones se plantean como procesos de reforma del estado, especialmente en el mundo periférico y el mundo ex socialista.

\subsection{Partidos politicos, sistema político y reforma estatal}

Toda transformación estatal presenta intensidades y trayectos distintos, así también puede responder a diferentes naturalezas. Puede tratarse de una reforma del estado o una reforma en el estado. En el primer caso, indiscutiblemente se refiere a una transformación de la naturaleza del estado: de un estado autocrático a uno democrático, o de un estado socialista a uno liberal, etcétera. En el segundo caso, se trata de modificaciones en el interior de la misma configuración estatal.

El objetivo fundamental del primer tipo de reforma es la trasformación del funcionamiento de los sistemas políticos, siempre se trata de estados autocráticos, en los que los sistemas jurídicos son formalmente públicos o liberales. Esto es, constitucionalmente comprenden los derechos individuales universales, incluidos los derechos políticos; en consecuencia, cuentan con un orden jurídico público básico o parcialmente moderno. Sin embargo, en las configuraciones autocráticas y/o autoritarias el funcionamiento del sistema político termina desvirtuando el contenido liberal y democrático de sus sistemas jurídicos. Éste es el caso predominante de los estados latinoamericanos. En virtud de ello, prevalecen esquemas rentistas entre gobernantes y 
segmentos privilegiados de gobernados, para quienes la ley tiene tratamiento especial. Grupos estrechamente vinculados a una cultura premoderna, como son los cacicazgos, el despotismo sindical, arreglos corporativistas autoritarios regidos por alianzas y contubernios con grupos u organizaciones políticas, etc., las democracias y los derechos liberales han sido históricamente conculcados por los arreglos cupulares que se han coagulado en las entrañas de las configuraciones periféricas. Tanto las transiciones a la democracia como las reformas del estado se desarrollan en medio de este contexto.

En México, los contubernio s y privilegios no sólo se establecen entre la élite gobernante y los empresarios de la vida económica-asunto que, siendo cierto, suscita la desaprobación airada de la crítica «de izquierda»-, sino también con otro segmento de empresarios, los de la vida política, estos es, los dirigentes de partidos. El establecimiento de un sistema de privilegios y concesiones a grupos, incluidos los partidos de oposición, mediante la compra de consensos y complicidades, es lo que ha permitido la célebre y elogiada «disciplina política», tanto entre las burocracias multipartidistas como entre las élites políticas. Pese a esta situación, aparentemente de intercambios entre iguales, los líderes u organizaciones, sobre todo opositores, tienen cuidado de no pasar los límites, más o menos evidentes, marcados por las élites estatales. Cuando la mesura en la oposición llega a regir los intereses de su propia organización, se engendra en sus dirigentes ciertas actitudes de subordinación política respecto de quien tiene el mando estatal, aun cuando hubiera un momento previo de obligar al gobierno a ser interlocutor. Ello no puede dejar de impactar, por supuesto, el proceso político: desde las elecciones nacionales hasta una política simple de recolección de basura; porque siempre está abierta la posibilidad de llegar a «arreglos» cupulares, donde todos ganen algo, sin que tengan que dar cuentas a los gobernados.

Ante ello, podemos fácilmente deducir las características generales de las políticas gubernamentales. En éstas existe prevalencia de un estilo burocratizado y además estructura- do por los grupos rentistas del sistema, como son las formaciones de monopolios mediante concesiones burocráticas, por mencionar sólo una cuestión. En las políticas gubernamentales, sexenio a sexenio, vemos ausente el carácter público. Es decir, están lejos de ser diseñadas para maximizar el bienestar de los individuos mediante una gestión pública eficiente, y en cambio, responde más a los intereses particulares de quienes están involucrados directamente en ellas. Y en esto, la relevancia de los partidos políticos no es poca. Mientras el concepto de partido nos advierte que éstos son vehículos de expresión de los problemas sociales, en el caso de partidos 
cuyas dirigencias gozan de prebendas y privilegios, sería difícil encontrar tal función.

El sistema político mexicano simplemente no es efectivamente democrático aunque esté estipulado jurídicamente. La realización periódica de elecciones lo ha legitimado como democracia, sin embargo, son elecciones seudocompetitivas y manipuladas; nos dice Rouquié: «elecciones sin sorpresas» basadas en el control de los votos, de partidos controlados, manipulación estatal y clientelismo. (Hermet, Rouquié y Linz, 1982) Brevemente podemos describir las características derivadas de las elecciones sin sorpresa: la virtual anulación de la división de poderes, la no alternancia del poder, la inexistencia, de facto, del federalismo, el control presidencial cuasi absoluto sobre el club político-partidista y, por la discrecionalidad del gobernante en turno en la toma de decisiones estatales. Con igual relevancia, podemos señalar -de incumbencia económica, pero debido a las características anteriormente descritas en este tipo de organizaciones estatales- el sobreendeudamiento público, las medidas inflacionarias, las tasas impositivas excesivas, etc.(Bazúa y Valenti, 1993)

La reforma del estado mexicano comprende, pues, toda una transformación radical de la estructura estatal que habita todo tipo de comportamiento pernicioso para los ciudadanos.

\subsection{Liberalización politica y limites de los partidos}

Podemos sostener que en México no ha habido una transición política ni mucho menos una reforma del estado como se presumió en el sexenio salinista. Se trata simplemente de reformas «de maquillaje», abocadas a cuestiones legislativas o a la administración pública pero dejando intactas las estructuras propias del estado. Algunos politólogos contemporáneos hablan de procesos de liberalización (Dahl, 1989). Estos consisten en la amplitud de los derechos y libertades políticas, la atenuación de la censura en los medios masivos de comunicación, el acceso de la oposición a puestos de autoridad de escaso poder, ampliación del debate sobre los asuntos públicos, entre otros. (Huntington 1994)

En México se ha socializado con cierto arraigo el tema de la transición política y la reforma del estado. Pese a ello, ha habido tres reformas electorales que han dejado intacta la fraudeabilidad del sistema electoral, específicamente en el padrón electoral. En éste, se ha probado públicamente la posibilidad de la multicredencialización, que significa el que un individuo pueda obtener (en las últimas y anteriores elecciones) más de una credencial con nombres y 
domicilios falsos y con su misma fotografía. (Bazúa, 1994) Si a esto le agregamos, todavía, los innumerables «electores fantasmas», registros falsos de personas inexistentes, reconocidos por el Instituto Federal Electoral de estar incluidos en el padrón, (Barberán, 1994) y la ubicación de «manzanas fantasmas» (Rodríguez, 1995) descubiertas posteriormente en el registro de electores, podemos damos cuenta de un panorama poco alentador del lugar que tenemos como mexicanos en el mundo de los estados en transición.

De nueva cuenta, el debate entre intelectuales, partidos y gobierno es el de una nueva reforma electoral. Sin embargo, las cuestiones enumeradas líneas arriba han sido totalmente ignoradas. Una genuina transición a la democracia adquiere su fuerza desde el momento en que garantiza a todos y cada uno de los ciudadanos el derecho fundamental de elegir periódicamente a sus gobernantes, sin control alguno sobre sus preferencias electorales. Más aún, una genuina transición pone sobre la mesa los puntos de intervención que son decisivos para que el régimen anterior pierda el atributo que lo convierte en autocrático o autoritario.

Por otra parte, la alternancia del poder -que podría ser un indicador sobre el control electoral ejercido desde el gobierno- no implica una apertura democrática, ni en México ni en ningún otro país en el que no esté garantizada la limpieza electoral. Pues ésta puede ser producto sólo de una transacción o pacto entre la oposición y el partido gobernante, sin más conflicto que el que pueda suscitarse por desavenencias en el precio de tal transacción; es decir, a cambio de qué puede darse una alternancia en el poder sin que se garantice mediante una elección limpia. El esfuerzo electoral, pues, se reduce a una relación clientelista de contactos personales y presiones sobre grupos pequeños, forma sofisticada de persuadir a las masas como si fuese una elección efectiva. (Linz, 1986) Mientras exista el control de los votos, el fraude electoral, con una oposición clientelista, y con una opinión pública manipulada y de baja calidad, seguirá existiendo sólo un proceso de liberalización controlado sin avance alguno en el proceso democratizador.

En fin, el sistema político mexicano está marcado por el agotamiento de las prácticas políticas tradicionales de sus actores, por el ventilamiento público de los niveles de corrupción que han descompuesto los más diversos espacios de la vida estatal mexicana y por las luchas internas de aniquilamiento entre los propios miembros del régimen.

Ahora pregunto: ¿cuál ha sido el papel de los partidos políticos en México, frente al panorama descrito anteriormente? También he querido encontrar respuestas aunque estas parecerían ser muy obvias. Por supuesto, cada organización partidaria puede ser objeto de un análisis profundo, pero 
cualquier análisis serio tendría que modelar las decisiones que toman sus dirigencias cuando se enfrentan al momento de incidir en la agenda gubernamental y, más específicamente, en la agenda de la transición. Y es éste el énfasis que quiero hacer.

Los partidos políticos, especialmente los de oposición, mantienen una actitud inerte y disimulada frente al carácter autocrático del estado mexicano. ${ }^{5}$ Han cuestionado ferozmente la reforma económica y han manipulado, y suprimido los temas candentes de lo que requiere una reforma política. Han legitimado una perestroika sin glasnot, expresión que fue utilizada para designar la estrategia salinista. En primer término, la estabilidad sociopolítica en México parece ser la prioridad número uno para todos. Todos quiere decir la élite norteamericana, el gobierno mexicano, los partidos políticos y la inerte ciudadanía, que parece comportarse como espectador de los avatares por los que atraviesa su estado.

Ante esta prioridad, parecería que los partidos políticos mexicanos han invertido su función de canalizadores, como agencias de expresión y representación de asuntos y problemas de interés público, para convertirse en agencias de expresión de la «razón de estado». El tema electoral es, por excelencia, el ejemplo. Con la actitud tolerante, pacificadora y «conciliadora», las dirigencias opositoras han soslayado el eje vector de toda transición política: el sufragio efectivo. Ello implica, sin temor a equivocarme, que la lectura hermenéutica de la situación estatal actual por parte de las dirigencias partidistas es que si las elecciones no son controladas, las probabilidades de que pierda el PRI se elevarían significativamente. Y ante este riesgo podrían profundizarse las fracturas institucionales del estado. Por tanto, habría mayor ingobernabilidad, un sistema económico más precario, los partidos políticos lucharían por conseguir votos -en vez de privilegios gubernamentales- a costa de la crítica consistente y sistemática del gobierno, etcétera.

\section{Nota Final}

En este contexto, podríamos aseverar que los partidos políticos como principales actores de una genuina transición política y, más aun, de una profunda reforma estatal en México son intrascendentes. La función que teóricamente tendrían que desempeñar sería la desestructuración de la red de relaciones

5 Es vital señalar que en el caso del PRO, esta afirmación resulta especialmente válida desde el acceso y la consolidación de la facción muñozledista, cuyo desempeño ha contrastado notablemente tanto con el discurso con el que se formó este partido, como con la actuación anterior, de 1988 a 1994 
informales e ilegales dentro del sistema político que obstaculizan cualquier avance en este sentido. Otra cuestión, asimismo, sería mostrar un mínimo de voluntad política para reivindicar los instrumentos que garanticen la efectividad de los procesos electorales. Por el contrario, la postura abierta de los dirigentes partidistas ha sido la de desviar principalmente el tema del padrón electoral y sustituirlo por temas de menos relevancia para el proceso de transición como es el caso del nombramiento del director del organismo administrador de las elecciones.

No obstante, los partidos políticos, si bien son intrascendentes para iniciar un verdadero proceso de transición, son sumamente trascendentes para el juego político del gobierno en turno, al volverse -con el sólo hecho de su existencia- instancias legitimadoras de un proceso caracterizado por la simulación. Pues, ante los ojos de la opinión pública internacional y de los propios mexicanos, estamos de facto ante un sistema de partidos, donde la oposición empieza a tener mayor presencia en los puestos de autoridad -caso concreto el PAN, vía negociación partido-gobierno- con la pretensión de desplazar el sistema priísta.

Así pues, sólo puede esperarse una transición real despartizando el proceso. Esto puede significar la creación de una «mesa ampliada» de negociaciones públicas. Sobre la base de una agenda de decisiones elaborada democráticamente, es decir, elaborada a lo largo de un período de discusión publica en todos los medios masivos, que tendría por resultado una lista de aspectos por decidir seleccionada por medio de elecciones. En tal mesa ampliada se definirían las decisiones estratégicas de reforma del estado y de construcción del estado democrático; las opciones finales adquirirían la forma de un referéndum, en donde podría incluso someterse a decisión la elaboración de una nueva constitución. En ella tendría que aparecer un sistema de correctivo s para evitar las colusiones que dañaron históricamente el carácter republicano, democrático y federal que en la letra ha tenido nuestro estado.

\section{Bibliografía}

Bazúa, Fernando y Giovanna Valenti, 1994: “Configuración estatal, gestión buropolítica y desarrollo económico. Acerca de los determinantes sociopolíticos del crecimiento económico moderno” en Canto, M. y Moreno, Pedro, Reforma del estado y política social. México: uam-x.

Bazúa, Fernando y Giovanna Valenti, 1993: «Cómo hacer del estado un bien público» Sociológica, mayo-agosto. México: uam-i.

Bobbio, Norberto, 1986: El futuro de la democracia. México: FCE. 
Dahl, Robert, 1989: La poliarquia. Participación y oposición. Madrid: Tecnos. Hermet, Guy., A Rouquié, y J. J Linz, 1982: ¿Para qué sirven las elecciones? México: FCE.

Huntington, Samuel, 1994: La tercera ola. La democratización a finales del siglo XX. Buenos Aires: Paidós.

Janda, Kenneth, 1993: "Comparative Political Parties: Research and Theory”, en Political Science: The State of Discipline, Ada W. Finifter.

Panebianco, Angelo, 1990: Modelos de partido: organización y poder en los partidos politicos. Madrid: Alianza Editorial.

Sartori, Giovanni, 1980: Partidos y sistemas de partidos. Madrid: Alianza Editorial

Schmitter, Philippe, L Whitehead y G O’Donnell, 1988: Transiciones desde un gobierno autoritario, (4 vols.) Buenos Aires: Paidós. 